\title{
Encefalitis aguda en pacientes COVID-19: primer reporte de casos en Perú.
}

\author{
Acute encephalitis associated with SARS-CoV-2: first case report in Peru. \\ Elliot Barreto-Acevedo ${ }^{1, \text { a }}$, Evelyn Mariños ${ }^{1, \text { a }}$, Poul Espino ${ }^{1, \text { a }}$, Jhonatan Troncoso ${ }^{1, b}$, Luis Urbina ${ }^{1, b}$, Nashely \\ Valer ${ }^{1, b}$
}

\section{RESUMEN}

En el contexto de la pandemia de COVID-19, se han descrito formas clínicas atípicas, en las que predominan síntomas extrar-respiratorios; entre ellos han sido reportados casos de manifestaciones neurológicas concurrentes. En base a la identificación de coronavirus en el sistema nervioso central en el brote SARS-CoV del 2002, se ha planteado un potencial neurotropismo del SARS-CoV-2. En la literatura mundial se han descrito escasos pacientes con encefalitis aguda asociada a SARS-CoV-2. En este reporte les presentamos dos casos de pacientes peruanos con encefalitis aguda concurrente a COVID-19, revisamos la literatura y discutimos los posibles mecanismos de neurotropismo y neuro-invasión.

PALABRAS CLAVE: encefalitis, COVID-19, Perú.

\section{SUMMARY}

In the context of the COVID-19 pandemic, atypical clinical forms have been described, in which extra-respiratory symptoms predominate; among them, cases of concurrent neurological manifestations have been reported. Based on the coronavirus identification in the central nervous system in the 2002 SARS-CoV outbreak, a potential neurotropism of SARS-CoV-2 has been raised. Few patients with acute encephalitis associated with SARS-CoV-2 have been described in the world literature. In this report we present two cases of Peruvian patients with acute encephalitis concurrent to COVID-19, we reviewed the literature and discussed the possible mechanisms of neurotropism and neuroinvasion.

KEY WORDS: encephalitis, COVID-19, Peru.

\section{INTRODUCCIÓN}

El coronavirus 2 del síndrome respiratorio agudo severo (SARS-CoV-2), causante de la pandemia de la enfermedad por coronavirus 2019 (COVID-19), es un virus $\mathrm{ARN}$, que a través de su proteína $\mathrm{S}$ se fija al receptor de la enzima convertidora de angiotensina 2 (ECA-2) y puede invadir las células para replicarse en su interior. El receptor de la ECA-2 se suele expresar en el epitelio del tracto respiratorio, en el parénquima pulmonar, corazón, endotelio vascular, riñones, intestino delgado y testículos. En base a estudios de cerebros de diferentes especies de mamíferos, se conoce que los receptores ECA-2 también se expresarían en tejido cerebral, tanto en glías, neuronas y células endoteliales. En el brote por el virus SARSCoV en el 2002 - 2003, se reportaron hallazgos clínicos de compromiso encefálico y se logró identificar ARN de dicho virus en el líquido cefalorraquídeo (LCR), lo que permitió sustentar su neurotropismo (1-4).

\footnotetext{
Departamento de Neurología, Hospital Nacional Edgardo Rebagliati Martins, EsSalud. Lima, Perú.

a Médico Asistente Neurólogo

b Médico Residente de Neurología
} 
Desde el inicio de la pandemia actual, en China, Europa y Estados Unidos, se han publicado algunos reportes de patología y sintomatología neurológica asociada a la presentación de COVID-19, aun cuando el cuadro típico cursa con síntomas predominantemente respiratorios. Se han reportado casos de infartos cerebrales, crisis epilépticas, encefalopatía necrotizante hemorrágica aguda, mielitis transversa, síndrome de Guillain Barré, anosmia súbita aislada o temprana en el curso de la enfermedad acompañada o no de ageusia y cuadros confusionales agudos (512). Estas observaciones han despertado el interés por estudiar un potencial neurotropismo de este virus, que explique tales manifestaciones. En este reporte describimos los primeros 2 casos de pacientes peruanos con COVID-19, que presentaron concomitantemente encefalitis aguda, revisamos la literatura mundial reportada a la fecha y los probables mecanismos de neurotropismo del SARS-CoV-2.

\section{Caso 1}

Varón de 53 años, autosuficiente, trabajador de seguridad, procedente de Lima, sin historia de viajes al extranjero este año y sin historia conocida de contacto con paciente con COVID-19. Ingresó al servicio de emergencia del Hospital Nacional Edgardo Rebagliati Marttins-EsSalud el 15 de abril del presente año, con cuadro agudo de 4 días de enfermedad, caracterizado por fiebre, escalofríos, malestar general y 2 días antes de su ingreso se añade tos seca y dolor faríngeo; recibió solo paracetamol condicional a la fiebre. El día de su ingreso, además de persistir la fiebre, presentó cefalea, desorientación temporo-espacial y una crisis epiléptica focal motora (oculo-giria hacia la derecha y movimientos clónicos en extremidades derechas por 1 minuto) evidenciada por personal de enfermería de la emergencia. Se documentó temperatura de $38.5^{\circ} \mathrm{C}$ y leve taquipnea $22 \mathrm{rpm}$, el examen cardiovascular y pulmonar fueron normales. La tomografía cerebral y la radiografía de tórax no evidenciaron alteraciones (figura 1 (A)). Le realizaron estudio serológico de inmunoglobulinas (Ig) para SARS-CoV-2, siendo negativo para IgM e IgG. Es evaluado entonces por el neurólogo, quien evidencia a un paciente despierto, inatento, con mirada errática, no respondía a preguntas, ni obedecía órdenes, presentaba rigidez de nuca $(++)$, no Kernig ni Brudzinski, la fuerza en extremidades era normal y no había compromiso de nervios craneales, ni signos piramidales. Se sugirió realizar RT-PCR para SARS-CoV-2 a partir de hisopado nasofaríngeo. Fue hospitalizado; inicialmente no se logró realizar la punción lumbar por que el paciente cursó con agitación psicomotriz. A las 48 horas, se recabó el resultado del hisopado naso-faríngeo, siendo este positivo para SARS-CoV-2. Se le realizó una tomografía de tórax, que evidenció patrón pulmonar de vidrio deslustrado bilateral (figura 1 (B)). A los 4 días de su ingreso se realizó punción lumbar, siendo el resultado del citoquímico del LCR: 4 células $/ \mathrm{mm}^{3}$ (linfomononucleares), proteínas $180 \mathrm{mg} / \mathrm{dL}$, glucosa $69 \mathrm{mg} / \mathrm{dL}$ y Pandy negativo. Los extendidos de Gram para gérmenes comunes y BAAR fueron negativos. El hemograma evidenció linfopenia absoluta de 700/uL sin leucopenia. El dímero D fue de 2,3 ug/dL, otros parámetros de la analítica sérica fueron normales. El paciente recibió fenitoina 100mg EV cada 8 horas, aciclovir $700 \mathrm{mg}$ EV cada 8 horas que fue suspendido
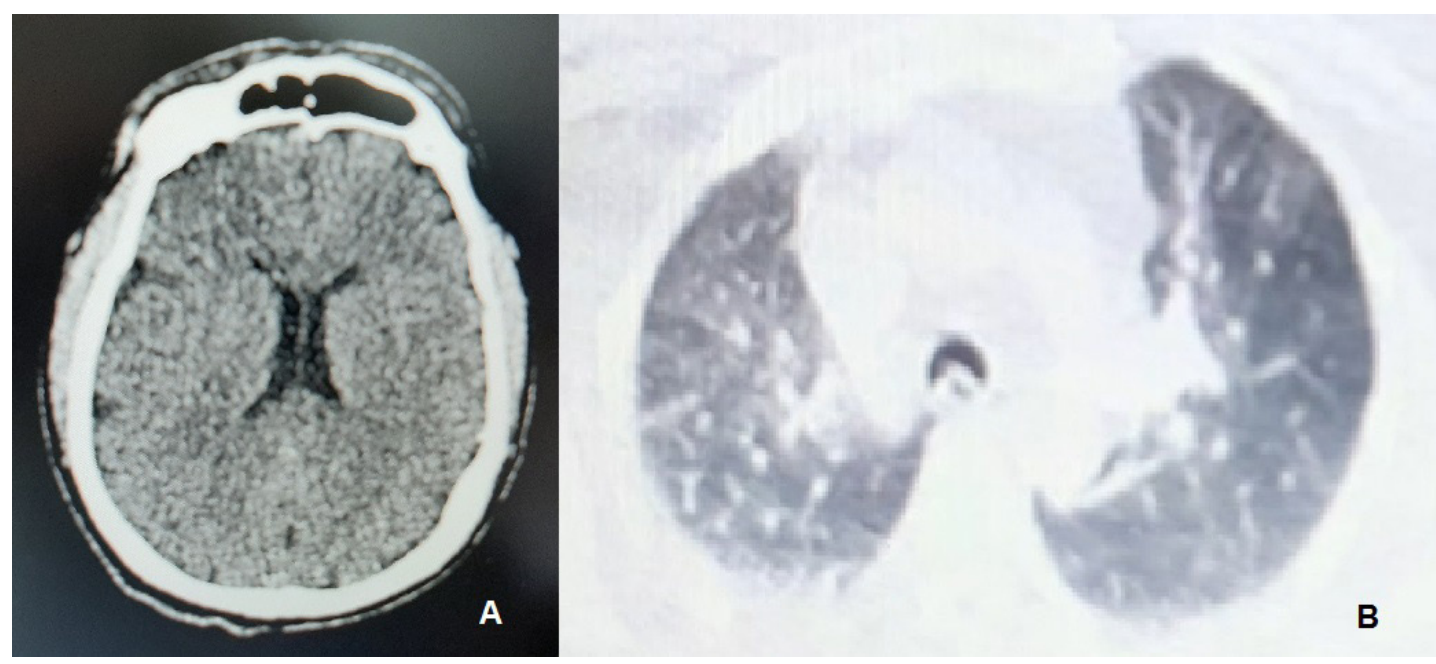

Figura 1. Tomografía de cerebro sin lesión (A). Tomografía de tórax, patrón pulmonar intersticial en vidrio deslustrado (B) 
a las 48 horas cuando se diagnosticó COVID-19, además de tratamiento de soporte con pronación periódica, fluidos y oxigenoterapia por mascara de reservorio. El cociente $\mathrm{PaO} 2 / \mathrm{FiO}_{2}$ se mantuvo entre 280 y $300 \mathrm{mmHg}$ y durante su estancia hospitalaria evolucionó sin recurrencia de crisis epilépticas, despierto, encafalopático, orientado solo en persona, inatento y sin déficit neurológico focal. El noveno día de su evolución cursó con súbito empeoramiento de la función respiratoria y falleció. El paciente fue cremado.

Se envió una muestra del LCR para RT-PCR para SARS-CoV-2 al laboratorio del Instituto Nacional de Salud, pero no fue procesada hasta la fecha. Se nos informó que el laboratorio del Instituto Nacional de Salud, entidad encargada de procesar los test para SARS-CoV-2 en nuestro país, no procesaba RT-PCR en muestra diferentes a la del hisopado nasofaríngeo.

\section{Caso 2}

Paciente mujer de 48 años, ama de casa, con sobrepeso, procedente de Lima, sin viajes al extranjero en 2020 y sin historia conocida de contacto con paciente con COVID-19. Ingresó al servicio de emergencia del Hospital Nacional Edgardo Rebagliati MarttinsEsSalud el 11 de abril, con cuadro agudo de 2 días de enfermedad, caracterizado por malestar general, cefalea global moderada, somnolencia intermitente, alza térmica no cuantificada y relato compatible con crisis epiléptica tónico-clónico de inicio desconocido. Al examen neurológico, estaba despierta, orientada solo en persona, inatenta, sin signos meníngeos y sin signos de déficit neurológico focal. El examen cardiovascular y pulmonar fueron normales. La tomografía cerebral no evidenció alteraciones (Figura 2A). Fue ingresada y se le realizó punción lumbar, presentando el citoquímico del LCR 120 celulas $/ \mathrm{mm}^{3}$ (90\% de linfomononucleares), hiperproteinorraquia $(73,4 \mathrm{mg} / \mathrm{dL})$ y normoglucorraquia $(84 \mathrm{mg} / \mathrm{dL})$. Los extendidos de Gram para gérmenes comunes y BAAR fueron negativos. Fue transferida a neurología y se inició tratamiento con aciclovir EV $750 \mathrm{mg}$ EV cada 8 horas y fenitoina $100 \mathrm{mg}$ Ev cada 12 horas. A las 48 horas de su ingreso, por presentar fiebre persistente y en el contexto de la pandemia, le realizaron test serológico de Ig para SARS CoV-2 siendo el IgM e IgG negativos. La resonancia de encéfalo con gadolineo no evidenció anormalidades (Figura 2(B)). A los 10 días, la paciente persistía febril, con desorientación temporo-espacial, pero se encontraba más alerta, sin recurrencia de crisis epilépticas y sin cefalea. Sin embargo, presentó disminución leve en la saturación de oxígeno (SatO2 $90-91 \%$ ) y leve taquipnea (frecuencia respiratoria 22$23 \mathrm{rpm}$ ). Un familiar, entonces, reportó que al iniciar la enfermedad la paciente había aquejado de leve dolor faríngeo. Es entonces que se decide solicitar una tomografía de tórax (figura 2 (D)), RT-PCR para SARS-CoV-2 de hisopado nasofaríngeo y debido a la demora conocida en el resultado del hisopado, también se solicitó paralelamente una nueva prueba serológica para SARS CoV-2. La tomografía de tórax evidenció un patrón de vidrio deslustrado bilateral con bandas fibróticas bi-basales, el test serológico nuevamente salió negativo para $\operatorname{IgM}$ e $\operatorname{IgG}$, pero el RT-PCR fue positivo para SARS-CoV-2. Además, al replantear el caso, se determinaron 2 hechos relevantes: la paciente había recibido desde su ingreso y por 8 días dexametasona EV $16 \mathrm{mg} /$ día - a pesar de lo controversial del uso sistemático de corticoides en encefalitis aguda - con lo que se había reportado una leve mejoría en su estado de alerta y remisión de la cefalea. Por otro lado, cuando se obtuvo el diagnóstico de COVID-19, al décimo día de su ingreso, se hizo una revisión de los estudios realizados previamente y la paciente contaba ya con una tomografía de tórax del día 12 de abril (1 día después de su ingreso) y en esta tomografía ya se evidenciaba el patrón pulmonar intersticial de vidrio deslustrado e incluso era más acentuado que el observado en la tomografía de tórax de control (Figura 2 (C)). La paciente, a la fecha del
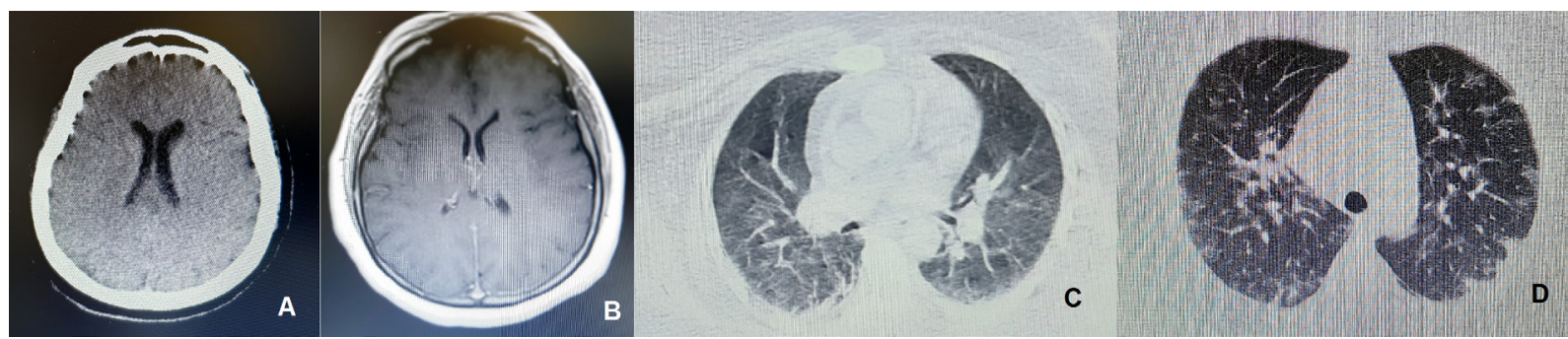

Figura 2. Tomografía de cerebro sin lesiones (A). Resonancia de encéfalo T1 contrastada sin lesiones (B). Tomografía de Tórax del 12 de Abril, evidencia patrón pulmonar deslustrado (C). Tomografía de Tórax del 22 de Abril, evidencia patrón pulmonar deslustrado pero con menor intensidad de la inflamación (D). 
Encefalitis aguda en pacientes COVID-19: primer reporte de casos en Perú.

reporte ha sido transferida a un área restringida para pacientes con COVID-19, persiste con leve dificultad respiratoria que ha requerido oxigenoterapia a bajo flujo por cánula nasal. No se obtuvo consentimiento de los familiares para realizar una punción lumbar de control.

\section{DISCUSIÓN}

En esta serie de 2 casos de COVID-19, reportamos la concurrencia de un cuadro clínico - biológico de encefalitis aguda. En ninguno de los 2 casos logramos demostrar la presencia del virus en LCR. El primer caso sigue una secuencia temporal definida con inicio de síntomas respiratorios patentes, pero llama la atención la instauración en pocos días, de un cuadro de encefalopatía aguda con rigidez de nuca evidente. Si bien la celularidad en el LCR estuvo en el límite superior de la normalidad, presentó marcada hiperproteinorraquia, la cual suele evidenciarse en cuadros neurológicos inflamatorios y degenerativos. Lamentablemente el desenlace fue fatal en pocos días, con un empeoramiento casi súbito de la dificultad respiratoria y solo recibió tratamiento de soporte.

El segundo caso siguió un curso clínico muy atípico, con un cuadro dominado por una presentación encefálica aguda al inicio; pero a los 10 días se añadieron síntomas respiratorios patentes; y es cuando se confirmó el diagnóstico de COVID-19 mediante el RT- PCR de hisopado nasofaríngeo. Entonces, podría plantearse la hipótesis de que la paciente haya ingresado por una encefalitis aguda viral no relacionada a SARS- CoV-2 y que haya sido contagiada de COVID-19 durante su estancia hospitalaria. Pero esta hipótesis se desestimó, cuando al hacer la revisión de los estudios paraclínicos realizados, nos encontramos con una tomografía de tórax realizada al día siguiente de su ingreso en la emergencia. Esta tomografía no había sido informada en la historia clínica, la cual ya mostraba un patrón pulmonar habitual de COVID-19, aun cuando la paciente no presentaba síntomas respiratorios en ese momento. En el contexto de la pandemia, se está haciendo más frecuente las solicitudes sistemáticas de tomografías o radiografías de tórax a todo paciente con fiebre. Por otro lado, es conocida la disociación clínico-radiológica en las neumonías atípicas virales; así al décimo día, cuando la paciente inició síntomas respiratorios, la tomografía de tórax de control evidenciaba más bien, una leve mejoría radiológica del patrón de vidrio deslustrado respecto a la tomografía inicial, aunque evidenciaba algunas bandas fibróticas basales. Una hipótesis para explicar esta mejoría radiológica podría ser que la paciente recibió 8 días de corticoides por la encefalitis y coincidentemente a los 2 días de la supresión de los corticoides, la paciente inició con leve taquipnea y leve disminución en la saturación de oxígeno. Ha sido reportado el uso de pulsos de metilprednisolona en fases tardías de COVID-19, justificando su utilidad para mitigar la llamada tormenta de citocinas. Incluso algunos reportes italianos sugieren su uso en fases más tempranas (13).

El estudio con mayor número de pacientes con COVID-19 que ha reportado manifestaciones neurológicas concomitantes, es el del Mao et al.; fue un estudio retrospectivo, con datos de 214 pacientes, encontraron clínica neurológica en un 36\% de pacientes; aun cuando no reportaron cuadros de encefalitis, ellos reportaron que un 7,5\% presentaba alteración de conciencia y un $0,5 \%$ presentaba crisis epilépticas. En su reporte no describen la realización de estudio de LCR a los pacientes. Los pacientes en enfermedad severa $(41 \%)$, fueron más propensos a presentar manifestaciones neurológicas (6); este hallazgo es coincidente con nuestro reporte, en especial el primer caso que evolucionó tórpidamente. Helms et al., en una serie francesa, con evidencia de hallazgos neurológicos clínicos y paraclínicos en 58 pacientes con síndrome de distrés respiratorio agudo por COVID-19, reportan que el 14\% presentaron las manifestaciones neurológicas a su ingreso a UCI y $67 \%$ presentaron algún hallazgo neurológico al retirar la sedación (26 pacientes presentaron encefalopatía). Respecto a los exámenes paraclínicos: se realizaron resonancia de encéfalo a 13 pacientes encefalopáticos, 8 evidenciaron realce leptomeningeo y se estudió el LCR en 7 pacientes, todos sin celularidad, 2 con bandas oligoclonales positivas y el RT-PCR para SARS CoV-2 en LCR fue negativo para los 7 pacientes. Los autores concluyen, en que no es posible determinar cuáles de los hallazgos neurológicos se deben a encefalopatía relacionada a enfermedad critica, cuales a respuesta inflamatoria encefálica mediada por citocinas y cuales serían específicos a la infección por SARS- Cov-2 (7). A la fecha, solo hay 6 reportes de caso en la literatura mundial sobre encefalitis o meningoencefalitis asociada a infección por SARS - CoV- 2 (tabla 1). Sin embargo; en todos ellos, excepto en dos, no se logró demostrar la presencia del virus en el LCR. El reporte de Zhou L et al., en el que señalan haber identificado el virus en LCR por secuenciación genética, es una descripción muy escueta que no brinda datos sobre el cuadro clínico, el tratamiento ni la evolución (1318). Las edades de estos casos fluctuaron entre $11 \mathrm{y}$ 60 años, correspondiendo 5 casos a pacientes adultos. 
Tabla 1. Reportes de casos de encefalitis aguda en pacientes con COVID-19.

\begin{tabular}{|c|c|c|c|c|c|c|c|c|c|}
\hline Autor & País & $\begin{array}{l}\text { Sexo y } \\
\text { edad } \\
\text { (años) }\end{array}$ & Antecedente & $\begin{array}{l}\text { Síntomas } \\
\text { respiratorios }\end{array}$ & $\begin{array}{l}\text { Clínica } \\
\text { neurológica }\end{array}$ & $\begin{array}{l}\text { Citoquímico } \\
\text { LCR }\end{array}$ & $\begin{array}{l}\text { Identificación } \\
\text { de SARS-CoV-2 } \\
\text { en LCR }\end{array}$ & Tratamiento & $\begin{array}{l}\text { Evolución } \\
\text { Neurológica }\end{array}$ \\
\hline $\begin{array}{l}\text { Duong } \\
\text { et al }\end{array}$ & USA & $\begin{array}{l}\text { Mujer } \\
41 \mathrm{a}\end{array}$ & $\begin{array}{l}\text { Obesa } \\
\text { DM-2 }\end{array}$ & Escasos & $\begin{array}{l}\text { Cefalea, fiebre, } \\
\text { somnolencia, } \\
\text { desorientación, } \\
\text { rigidez de nuca }\end{array}$ & $\begin{array}{l}\text { Células } \\
\text { (LMN): 70/ } \\
\text { mm3 } \\
\text { Proteinas:103 } \\
\text { mg/dL }\end{array}$ & $\begin{array}{l}\text { No se realizó el } \\
\text { estudio }\end{array}$ & Hidroxicloroquina & Mejoría \\
\hline Ye et al & China & $\begin{array}{l}\text { Varón } \\
\text { adulto }\end{array}$ & ¿? & $\mathrm{Si}$ & $\begin{array}{l}\text { Confusión } \\
\text { asociado a } \\
\text { floridos signos } \\
\text { meníngeos y } \\
\text { fiebre }\end{array}$ & normal & No se identifico & Manitol & Mejoría \\
\hline $\begin{array}{l}\text { McAbee G } \\
\text { et al }\end{array}$ & USA & $\begin{array}{l}\text { Varón } \\
11 \mathrm{a}\end{array}$ & ¿? & Sin síntomas & $\begin{array}{l}\text { Estatus } \\
\text { epiléptico } \\
\text { fiebre }\end{array}$ & $\begin{array}{l}\text { Células: } \\
16 / \mathrm{mm} 3 \\
\text { Proteínas } \\
97 \mathrm{mg} / \mathrm{dL}\end{array}$ & $\begin{array}{l}\text { No bien } \\
\text { precisado }\end{array}$ & & \\
\hline $\begin{array}{l}\text { Pilotto } \\
\text { et al. }\end{array}$ & Italia & $\begin{array}{l}\text { Varón } \\
60 \mathrm{a}\end{array}$ & ¿? & $\begin{array}{l}\text { Mínimos } \\
\text { síntomas }\end{array}$ & $\begin{array}{l}\text { Irritabilidad, } \\
\text { confusión, } \\
\text { deterioro } \\
\text { cognitivo, } \\
\text { apatía, mutismo } \\
\text { akinetico } \\
\text { fiebre }\end{array}$ & $\begin{array}{l}\text { Células } \\
\text { 18/mm3 } \\
\text { Proteínas } \\
696 \mathrm{mg} / \mathrm{dL}\end{array}$ & $\begin{array}{l}\text { RT-PCR para } \\
\text { SARS- CoV-2 } \\
\text { en LCR en } \\
2 \text { muestras } \\
\text { negativos }\end{array}$ & $\begin{array}{l}\text { Uso temprano de } \\
\text { metilprednisolona } \\
\text { al no evidenciar } \\
\text { mejoría con } \\
\text { hidroxicloroquina } \\
\text { mas Lopinavir/ } \\
\text { Ritonavir }\end{array}$ & $\begin{array}{l}\text { Mejoría rápida } \\
\text { significativa }\end{array}$ \\
\hline $\begin{array}{l}\text { Zhou L } \\
\text { et al }\end{array}$ & China & $\begin{array}{l}\text { Varón } \\
56 a\end{array}$ & ¿? & ¿? & $\begin{array}{l}\text { "encefalitis } \\
\text { aguda" }\end{array}$ & ¿? & $\begin{array}{l}\text { Identificación } \\
\text { por } \\
\text { secuenciación } \\
\text { genetica }\end{array}$ & & \\
\hline $\begin{array}{l}\text { Morigucho } \\
\text { et al }\end{array}$ & Japón & $\begin{array}{l}\text { Varón } \\
24 a\end{array}$ & No & Neumonía & $\begin{array}{l}\text { Cefalea, crisis } \\
\text { generalizada, } \\
\text { alteración de } \\
\text { conciencia, } \\
\text { rigidez de nuca, } \\
\text { fiebre }\end{array}$ & $\begin{array}{l}\text { Células: 12/ } \\
\text { mm3 (10 } \\
\text { LMN) }\end{array}$ & $\begin{array}{l}\text { Identificación } \\
\text { de ARN SARS- } \\
\text { CoV-2 en LCR }\end{array}$ & $\begin{array}{l}\text { Favipiravir } \\
\text { Corticoides } \\
\text { Antibióticos, } \\
\text { Levetiracetam, }\end{array}$ & $\begin{array}{l}\text { Evolución } \\
\text { tórpida con } \\
\text { frecuentes crisis } \\
\text { epilepticas, } \\
\text { neumonía } \\
\text { bacteriana } \\
\text { sobreagregada } \\
\text { y requirió de } \\
\text { ventilación } \\
\text { mecánica }\end{array}$ \\
\hline
\end{tabular}

Nuestros 2 casos también están en este rango. Los reportes incluyeron a 5 varones y 1 mujer; en nuestros casos tuvimos a un varón y una mujer. En general se ha descrito un predominio del sexo masculino en la presentación de COVID-19, sin tener una explicación definida para tal fenómeno; pero se ha propuesto factores hormonales, predominio de factores de riesgo como enfermedades cardiovasculares, obesidad y tabaquismo y una posible mayor exposición por menor posibilidad de aislamiento en varones. Nuestro primer caso no presentó factores de riesgo para formas severas de COVID-19 y la paciente del segundo caso tenía sobrepeso. En los reportes referidos, solo en el estudio de Duong et al., la paciente tenia obesidad y diabetes mellitus, en los otros 5 reportes no se hace explicita la presencia o ausencia de algún factor de riesgo. En 3 de los 6 casos reportados en la literatura mundial, sorprendentemente, los síntomas respiratorios fueron escasos, incluso en uno de ellos prácticamente estuvieron ausentes (13-18). Esto también ocurrió en nuestro segundo caso al inicio de la enfermedad y ello demoró el diagnóstico de COVID-19. Esto nos deja la lección que en el contexto de la pandemia hay casos atípicos con fiebre y sin síntomas respiratorios, que deberían ser estudiados desde un inicio para SARS-CoV-2; en especial si se encuentran signos concomitantes de compromiso encefálico.

Clínicamente, la alteración de la conciencia, de la cognición y los signos meníngeos asociados a fiebre fueron el común denominador en los casos reportados; tal como ocurrió en nuestros 2 pacientes. En nuestros casos además hubo crisis epilépticas desde el inicio de la enfermedad, las que también fueron reportadas en 2 de los 6 casos de las publicaciones referidas. Respecto a la celularidad en el LCR en los reportes referidos, esta fluctuó entre 0 a 70 células $/ \mathrm{mm}^{3}$, con predominio de linfomononucleares (LMN); pero hubo una tendencia a la baja celularidad (12 a 18 células $/ \mathrm{mm}^{3}$ en 3 reportes). En nuestros casos, un 
Encefalitis aguda en pacientes COVID-19: primer reporte de casos en Perú.

paciente presentó solo $4 \mathrm{LMN} / \mathrm{mm} 3$ y la otra paciente presentó 120 células $/ \mathrm{mm} 3 \quad(90 \% \quad$ LMN). Hubo hiperproteinorraquia en ambos pacientes sin consumo de glucosa, como suele evidenciarse en cuadros virales e inflamatorios. De los 6 casos reportados, se describe el tratamiento y la evolución neurológica en 4 pacientes: 2 con mejoría y uso de hidroxicloroquina en uno y de manitol en otro; uno con evolución favorable muy rápida y significativa al usar puslsos de metilpredinisolona luego de no encontrar mejoría con hidroxicloroquina mas lopinavir/ritonavir y un caso con evolución tórpida luego de usar favipiravir, levetiracetam y corticoides. Nuestro primer caso tuvo un desenlace fatal y recibió tratamiento de soporte con oxigenoterapia; inicialmente recibió aciclovir pero fue suspendido rápidamente al corroborarse COVID-19 $\mathrm{y}$ en el segundos caso, como ya fue descrito, se evidenció una leve mejoría neurológica con el uso de dexametasona $\mathrm{Ev}$ por 8 días, aunque también recibió aciclovir por 10 días. El caso reportado por Moringuchi et al; es el único con neuroimagen anormal: resonancia de encéfalo con hiperseñal en la difusión alrededor del ventrículo lateral derecho e hiperseñal mesial temporal derecha en FLAIR con leve atrofia hipocampal (18). En nuestros casos, ambos pacientes tuvieron tomografía de cerebro normal y la segunda paciente tuvo resonancia de encéfalo normal, en los otros 5 casos reportados mundialmente, las tomografías cerebrales fueron normales (13-17).

Hasta la fecha se debate el potencial neurotrópico y neuroinvasivo de SARS-CoV-2 y los mecanismos por los cuales se explique la observación de encefalitis aguda en algunos pacientes. Como ya fue señalado, los recetores ECA-2 a los cuales se fija el virus a través de la proteína $\mathrm{S}$, también se encuentran expresados en neuronas, glias y células del endotelio vascular cerebral. Se ha planteado que el ingreso de SARSCoV-2 al encéfalo podría ocurrir por 2 vías. Vía hematógena, atravesando la barrera hematoencefálica (BHE), mediante el mecanismo del caballo de Troya al ocultarse el virus al interior de un linfocito o previa inflamación de la BHE facilitando su apertura. $\mathrm{O}$ vía neural - trans-sináptica a través de la diseminación desde la mucosa nasal hacia el epitelio y tracto olfatorio, atravesando la placa cribiforme del etmoides. Este último mecanismo ha sido documentado en ratones transgénicos infectados por SARS-CoV y MERS-CoV vía intranasal. Las partículas virales fueron luego detectadas en neuronas cerebrales, principalmente del tronco cerebral y del tálamo. Este mecanismo de transmisión trans-sináptica a partir del epitelio nasal ha sido planteado para explicar al menos parcialmente los casos de súbita insuficiencia respiratoria observada en algunos pacientes afectados por CoVs. En pacientes con COVID-19, el mecanismo de transmisión trans-sináptica vía nasal ha sido planteado en base al hallazgo de un alto porcentaje de pacientes que presentan anosmia en una fase temprana de la enfermedad e incluso como único síntoma (anosmia aguda súbita aislada) en algunos casos. (1-3, $5,18,19)$

La fisiopatogenia de las infecciones virales graves está estrechamente relacionada con el desarrollo de un síndrome de respuesta inflamatoria sistémica (SRIS). Como en las infecciones por SARS- CoV y MERS$\mathrm{CoV}$; SARS-CoV-2 ha provocado fallecimientos que se han relacionado a falla de múltiples órganos, causada por SRIS. Este fenómeno, se debería a una respuesta hiperinmune, con la liberación de múltiples mediadores inflamatorios, en especial citocinas como la interleucina 6 y es conocido como tormenta de citocinas. Esta respuesta inflamatoria inmune ocurriría en una fase intermedia a tardía de la infección en los casos severos y podría generar una encefalopatía tóxica-inflamatoria y es probable que explique la descripción de casos con encefalopatía y algunos casos de encefalitis $(1-3,18,19)$.

En conclusión, algunos casos atípicos de COVID-19, pueden presentarse con un cuadro clínico de encefalitis aguda, el cual se debería tenerse en cuenta para sospechar de infección por SARS-CoV-2 en forma precoz en el contexto de la pandemia. Es muy temprano para afirmar sí en todos los casos, la afectación encefálica sea consecuencia directa de una potencial neuroinvasión del SARS-CoV-2 al encéfalo, pues podría ser una consecuencia de mecanismos indirectos, producto de la respuesta inflamatoria e inmune sistémica. Se requiere documentar clínica y para-clínicamente los casos de COVID-19 con manifestaciones neurológicas concomitantes, teniendo en cuenta siempre las medidas de bioseguridad.

\section{Correspondencia}

\author{
Dr. Elliot Barreto Acevedo \\ Hospital Nacional Edgardo Rebagliati Martins \\ Av. Rebagliati 490 Jesús María \\ Teléfono: 511-265-4901 anexo: 3081 \\ Correo electrónico: elliotba@hotmail.com
}

Este reporte de casos cuenta con autorización del Comité de ética de IETSI de EsSalud. 
Los autores no han recibido financiamiento de ninguna institución o persona. Los autores

no tienen conflictos de interés.

\section{REFERENCIAS BIBLIOGRAFICAS}

1. Nath A. Neurologic complications of coronavirus infections. Neurology. 2020; 94(21): 1-2.

2. Wu Y, Xu X, Chen Z, Duan J, Hashimoto K, Yang $\mathrm{L}$, et al .Nervous system involvement after infection with COVID-19 and other coronavirus. Brain, Bahavior and Inmunity. 2020; Por publicarse. Doi: http://doi.org/10.1016/j.bbi.2020.03.031.

3. Baig A, Khaleeq A, Ali U, Syeda H. Evidence of the COVID-19 Virus Targeting the CNS: Tissue Distribution, Host- Virus Interaction, and Proposed Neurotropic Mechanisms. ACS Chem Neurosci 2020; 11:995-8.

4. Hung EC, Chim SS, Chan Pk. Detection of SARS coronavirus RNA in the cerebrospinal fluid of a patient with severe acute respiratory syndrome. Clin Chem. 2003; 49: 2108-09.

5. Gane S, Kelly Ch, Hopkins C. Isoleted sudden onset anosmia in COVID-19 infection. A novel syndrome? Rhinology. 2020; 1: 58. Doi: https://doi.org/10.4193/ Rhin 20.114

6. Mao L, Jin H, Wang M, Hu Y, Chen Sh, He Q, et al. Neurologic Manifestations of Hospitalized Patients With Coronavirus Disease 2019 in Wuhan, China. JAMA Neurol 2020; por publicarse. Doi:0.1001/jamaneurol.2020.1127.

7. Helms J, Kremer S, Merdji H, Clere-Jehl R, Schenck M. Nuerological features in Severe SARS-CoV-2 Infection. N Engl . 2020; por publicarse. Doi:10.10.56/ NEJMc2008597.

8. Toscano G, Palmerini F, Ravaglia S, Ruiz L, Invernizzi P, Cuzzoni M, el al. Guillain Barré Syndrome Associated with SARS-CoV-2. N Engl Med. 2020; por publicarse. Doi:10.10.56/ NEJMc2009191.

9. Zhao H, Shen D, Zhou H, Liu J, Chen Sh. Guillain Barré syndrome associated with SARS-Cov-2 infection: causality or coincidence? Lancet. 2020; por publicarse. Doi: https://doi.org/10.1016/S14744422(20)30109-5
10. Gutiérrez-Ortiz C, Méndez A, Rodrigo-Rey S, PedroMurillo E, Bermejo-Guerrero L, et al. Miller Fisher Syndrome and polineuritis cranialis in COVID-19. Neurology 2020; por publicarse. Doi: 10.1212/ WNL.0000000000009619

11. Poyiadji N, Shahin G, Noujaim D, Stone M, Patel S, Griffith B. COVID-19-associated Acute Hemorrhagic Necrotizing Encephalopathy: CT and MRI Features. Radiology.2020; por publicarse. Doi: 10.1148/radiol.2020201187

12. Zhao K, Huang J, Dai D, Feng Y, Liu L, Nie S, et al. Acute mielitis after SARS-CoV-2 infection: a case report. medRxiv. 2010; por publicarse. doi: https:// doi.org/10.1101/2020.03.16.20035105

13. Pilotto A, Odolini S, Masciocchi S, Comelli A, Volonghi I, Gazzina S, et al. Steroidresponsive severe encephalopathy in SARS-CoV-2 infection. medRxiv. por publicarse. doi: https://doi. org/10.1101/2020.04.12.20062646

14. Xu P, Liu A. Meningoencephalitis without respiratory failure in a young female patient with COVID-19 Infection in Downtown Los Angeles, Early April 2020. Brain, Behavior, and Immunity 2020; por publicarse. Doi: https://doi.org/10.1016/j.bbi.2020.04.024

15. Mingxiang Y, Yi R, Tangfeng L. Encephalitis as a clinical manifestation of COVID-19. Brain, Behavior, and Immunity 2020; por publicarse. Doi: https://doi. org/10.1016/j.bbi.2020.04.017

16. McAbee GN, Brosgol Y, Pavlakis S, Agha R, Gaffoor M, Encephalitis Associated with COVID-19 Infection in an 11 Year-Old Child, Pediatric Neurology. 2020; por publicarse. Doi: https://doi. org/10.1016/j.pediatrneurol.2020.04.013

17. Zhou L, Zhang M, Wang J, Gao J. SARS- CoV2: Underestimated damage to nervous system. Travel Medicine and Infectious Disease. 2020; por publicarse. Doi: https://doi.org/10.1016/j.tmaid.2020.101642

18. Moriguchi T, Harii N, Goto J, Harada D, Sugawara $\mathrm{H}$, Takamino J. A first case of meningitis/encephalitis associated with SARS-Coronavirus-2. International Journal of Infectious . 2020; 94:55-58.

19. Li Y, Bai W, Hashikawa T. The neuroinvasive potential of SARS-CoV2 may a role in the respiratory failure of COVID-19 patients. J Med Virol 2020;1:14. Doi:10.1002/jmv.25728 